\title{
Postharvest soft rot on Citrullus vulgaris caused by Rhizopus oryzae in South Korea
}

\author{
Jin-Hyeuk Kwon • Jeong-Seok Ha • Jinwoo Kim
}

Received: 12 December 2013 / Accepted: 14 March 2014 / Published online: 30 March 2014

(C) Australasian Plant Pathology Society Inc. 2014

\begin{abstract}
During the summers of 2010 and 2011, a disease suspected to be Rhizopus soft rot was observed on watermelon at commercial markets in Jinju, South Korea. The infected parts of the mature fruits appeared water-soaked at first, and then softened and rotted rapidly. White mycelia grew from the primary infection site and gradually covered the fruit with tufted whisker-like gray sporangia and sporangiophores. To confirm the identity of the fungus, the complete internal transcribed spacer (ITS) rDNA sequence was amplified and sequenced. On the basis of the mycological characteristics, molecular identification and pathogenicity, the fungus was identified as Rhyzopus oryzae. This is the first note of $R$. oryzae as a postharvest pathogen of watermelon in Korea.
\end{abstract}

Keywords Rhizopus oryzae - Rhizopus soft rot ·

Watermelon · rDNA spacer sequence

Watermelon (Citrullus vulgaris) is one of popular fruit consumed widely throughout the world for its fleshy, refreshing fruits. It is a natural and rich source of the antioxidant lycopene (Hall 2004) and non-essential amino acid citrulline, which is known to relax and dilate blood vessels (Rimando and Perkins-Veazie 2005). Watermelon is susceptible to a variety of fungal, bacterial and viral diseases at various stages of its growth (Sharma and Khan 1991; Roberts and Kucharck 2003).

J.-H. Kwon · J.-S. Ha

Gyeongsangnam-do Agricultural Research and Extension Services, Jinju 660-360, South Korea

J. $\operatorname{Kim}(\bowtie)$

Division of Applied Life Science (BK21 Plus) and Institute of Agriculture and Life Sciences, Gyeongsang National University, Jinju 660-701, South Korea

e-mail: jinwoo@gnu.ac.kr
During the summers of 2010 and 2011, a disease suspected to be Rhizopus soft rot was observed on watermelon at commercial markets in Jinju, South Korea. Wounded mature fruits were often affected, but undamaged or immature watermelons were not attacked. The infections started from cracks that occurred at harvest. The infected parts of the mature fruits appeared water-soaked at first, and then softened and rotted rapidly. White mycelia grew from the primary infection site and gradually covered the fruit with tufted whisker-like gray sporangia and sporangiophores (Fig. 1). Ten diseased fruit of watermelon were sampled, and isolation was performed on potato dextrose agar (PDA) as described previously (Kwon et al. 2010). Briefly, fungal mycelial tips produced on the diseased watermelon fruits were transferred to PDA. Ten Rhizopus isolates (one from each sample) were obtained from the diseased watermelon fruits. The colonies of fungus grown on PDA were white and cottony at first, then became heavily speckled with the appearance of sporangia and finally became brownish-grey to blackish-grey, and spread rapidly with stolons protruding from rhizoids to the substrate at various points. Sporangiospores were unequal, numerous, irregular, sub-globose or oval, angular with striations, and 4-11 $\mu \mathrm{m}$ in length. Sporangiophores were usually straight, smoothwalled, simple or branched, non-septate, long, and arose from stolons opposite rhizoids usually in groups of 3-5 or more, and 6-20 $\mu \mathrm{m}$ in diameter. Sporangia were globose, 50$200 \mu \mathrm{m}$ in diameter, and white at first and later black with many spores. Columellae were globose to sub-globose, pale brown, and $80-110 \mu \mathrm{m}$ in diameter. Rhizoids and stolons were dark brown. Two Rhizopus species, R. stolonifer and $R$. oryzae, are known to cause soft rots of cucurbit plants in South Korea (The Korean Society of Plant Pathology 2009; Kwon et al. 2010). Temperature growth studies are important to distinguish between the two species: $R$. stolonifer grows at $30{ }^{\circ} \mathrm{C}$ but not at $37{ }^{\circ} \mathrm{C}$, whereas $R$. oryzae grows at $40{ }^{\circ} \mathrm{C}$ (Schipper and Stalpers 2003). The mycelium growth rate of all 


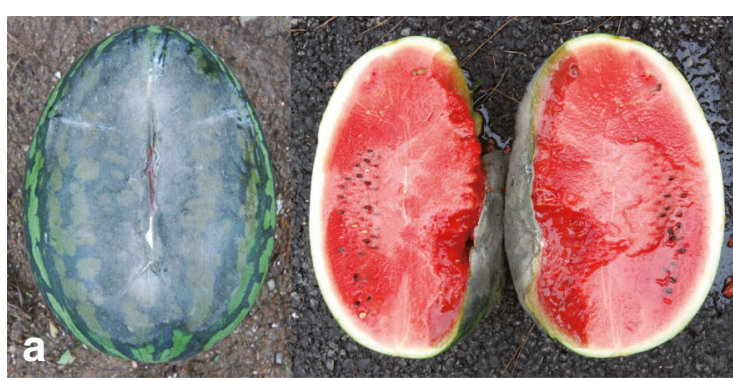

Fig. 1 Symptoms of soft rot on watermelon caused by Rhizopus oryzae. a Typical symptoms of Rhizopus soft rot on fruit and a longitudinal section of infected fruit; b symptom showing water-soaked appearance
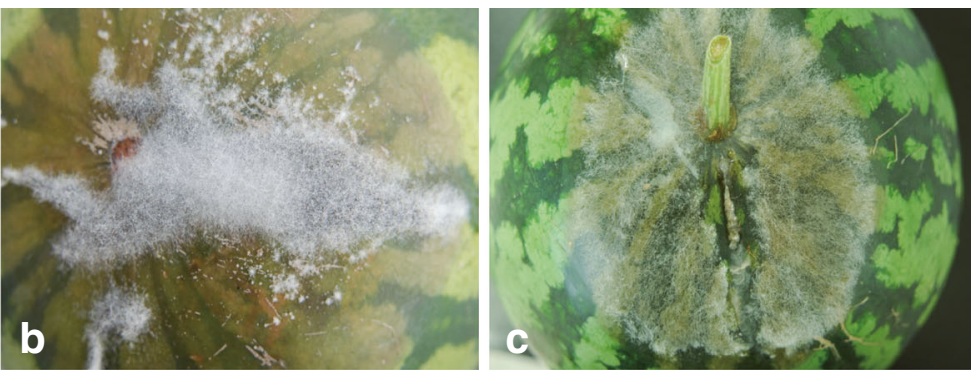

and mycelium sporangia on the fruit surface; $\mathbf{c}$ symptoms induced by artificial inoculation after 4 days of incubation

(KACC 45160), National Academy of Agricultural Science, Rural Development Administration, Suwon, South Korea.

To test pathogenicity, inoculum of a representative fungal isolate (KACC 45160) was prepared as described previously (Kwon et al. 2010). The surfaces of six fruits were wounded by scratching lightly with a sterile scalpel and drop-inoculated with $100 \mu \mathrm{l}$ of a conidium suspension $\left(10^{4}\right.$ conidia/ml), and three control fruits were inoculated with $100 \mu$ l of sterile deposited with the Korean Agricultural Culture Collection
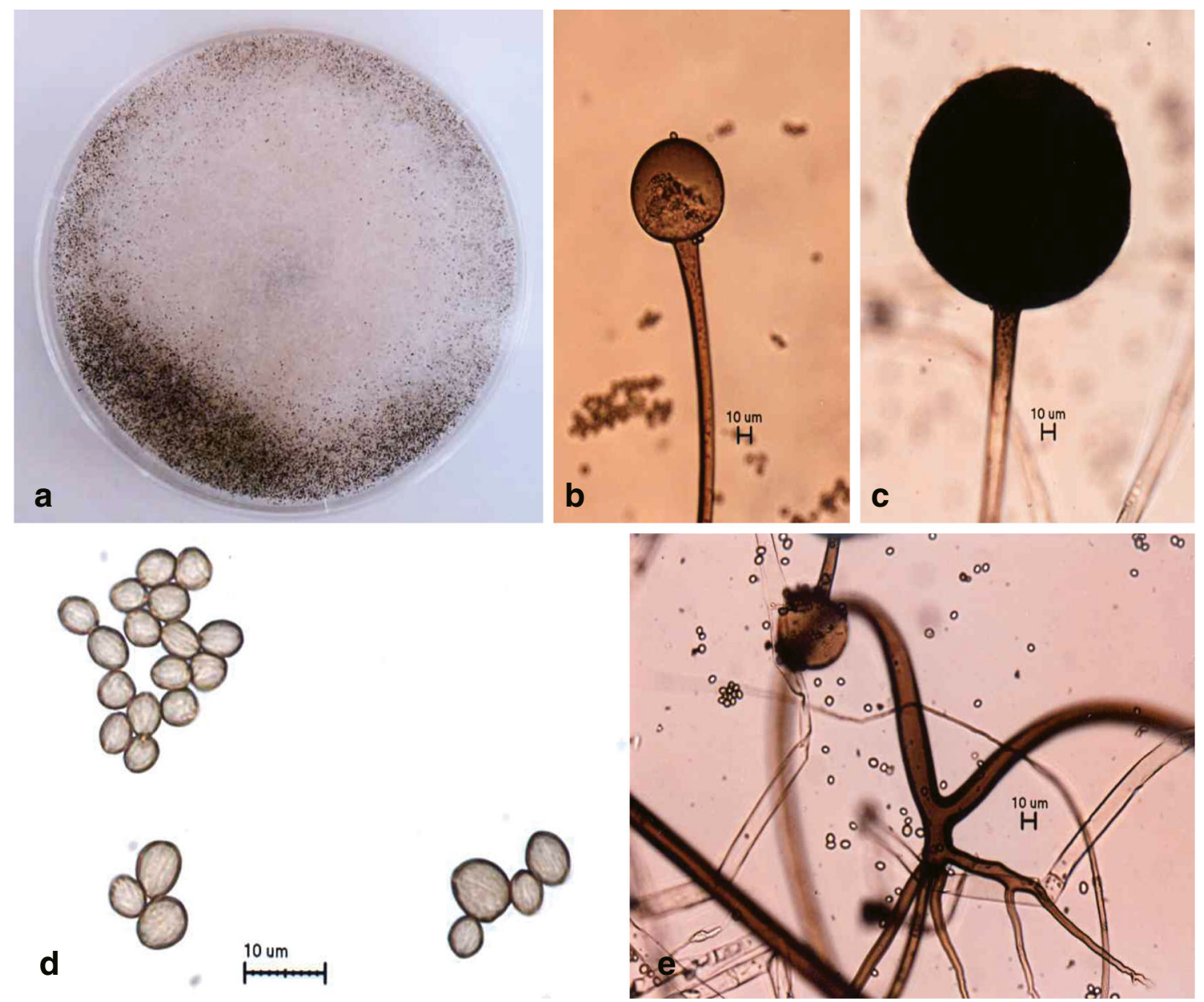

Fig. 2 Morphological characteristics of Rhizopus oryzae isolated from watermelon. a Colony on PDA 7 days after inoculation; b sporangium and sporangiophore; c columella; $\mathbf{d}$ sporangiospores; e rhizoid 
Fig. 3 Phylogenetic tree using ITS sequences showing closest known relatives of Rhizopus oryzae. DNA sequences from the NCBI nucleotide database were aligned using ClustalW and a phylogenetic tree was constructed using the neighbor-joining method and visualized with TreeView. Numbers above the branches indicate the bootstrap values. Bars indicate number of nucleotide substitutions per site. The culture isolated from watermelon is in bold

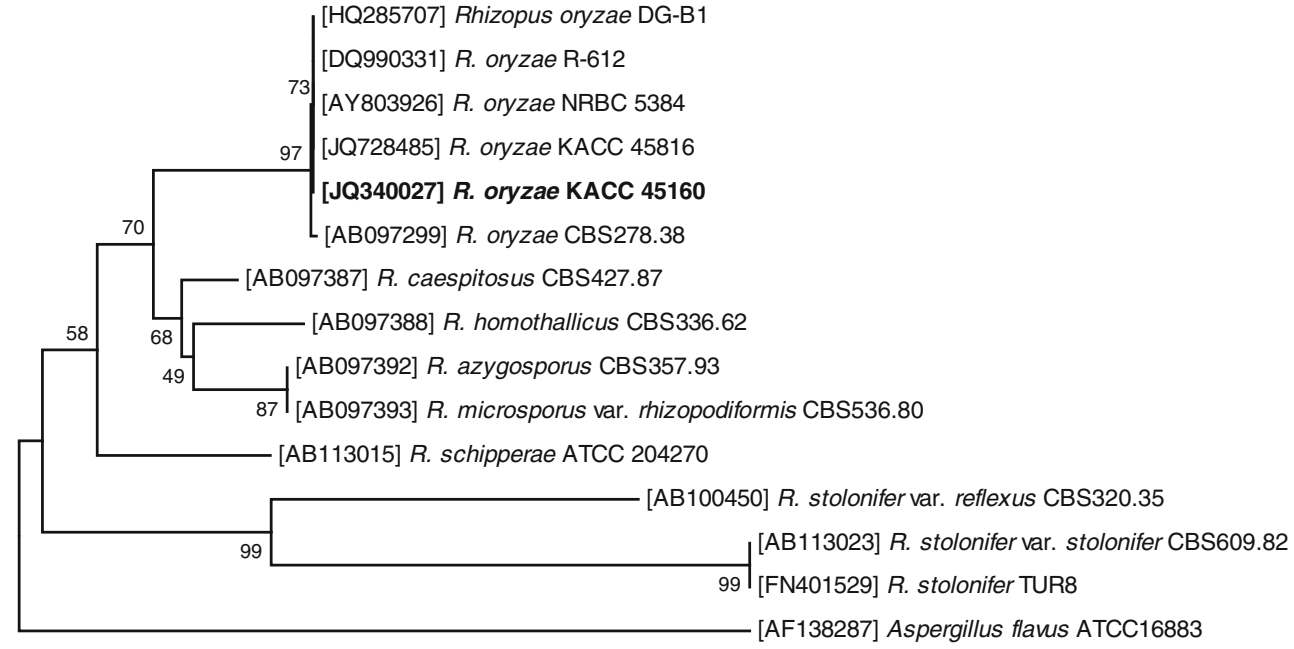

$\longmapsto .1$ water. The inoculated fruits were placed in a vinyl bag at $25^{\circ} \mathrm{C}$ with $100 \%$ relative humidity for $48 \mathrm{~h}$ and then placed on a laboratory table at room temperature. Symptoms appeared 5 days after inoculation, whereas controls were asymptomatic. The symptoms were identical with those of the naturallyoccurring disease. Morphological characteristics of the reisolated fungus from the inoculated fruits were the same as those from the original isolate, fulfilling Koch's postulates.

Due to the high economic value of watermelon, identification of this progressing fungal disease is important. To confirm the identity of the causal fungus, the complete internal transcribed spacer region (ITS) of the rRNA gene of the isolate was amplified using primers ITS1 (5'-TCCGTAGG TGAACCTGCGG-3') and ITS4 (5'-TCCTCCGCTTATTG ATATGC-3') (White et al. 1990). Total DNA was isolated using the Exgene Plant-Fungal SV Mini kit (Geneall Biotechnology Co., Seoul, Korea), following the manufacturer's instructions. The polymerase chain reaction (PCR) mixture contained 5 units Taq polymerase (TaKaRa, Tokyo, Japan), $1 \times$ PCR buffer, $0.2 \mathrm{mM}$ of each dNTP, $10 \mathrm{nM}$ of each primer, and approximately $10 \mathrm{ng}$ fungal genomic DNA with the total volume adjusted to $50 \mu \mathrm{l}$ with sterile water. PCR was performed using an Astec PC 802 thermal cycler (Astec, Fukuoka, Japan) with the following thermal profile: $98{ }^{\circ} \mathrm{C}$ for $2 \mathrm{~min}$, followed by 30 cycles of $98^{\circ} \mathrm{C}$ for $30 \mathrm{~s}, 55^{\circ} \mathrm{C}$ for $30 \mathrm{~s}, 70{ }^{\circ} \mathrm{C}$ for $30 \mathrm{~s}$ and a final extension step of $72{ }^{\circ} \mathrm{C}$ for $4 \mathrm{~min}$. Amplified products were separated by electrophoresis on a $0.8 \%$ agarose gel in $1 \times$ TBE buffer at $100 \mathrm{~V}$ for $20 \mathrm{~min}$. PCR products were extracted after agarose gel electrophoresis using a gel extraction kit (Geneall Biotechnology Co., Seoul, Korea). Purified PCR products were cloned into the pGEM-T Easy Vector (Promega, Madison, WI, USA) to generate the plasmid pJW84. Sequencing was performed using a Bigdye Terminator Cycle Sequencing kit (Applied Biosystems, Foster City, CA, USA) with primers M13F and M13R, following the manufacturer's instructions. The resulting 627-bp of the ITS rRNA gene sequence was deposited in GenBank (Accession No. JQ340027). Phylogenetic analysis was performed using MEGA4 software employing the neighbor-joining method and the Tajima-Nei distance model (Tamura et al. 2007). Previously published ITS sequences from $R$. oryzae strains were included for reference, and Aspergillus flavus ATCC 16883 (GenBank Accession No. AF13883) was used as an out-group (Fig. 3). The resulting sequence exactly matched sequences (GenBank Accession Nos. HQ285707 and AY803926) of R. oryzae.

On the basis of the mycological characteristics, molecular identification and pathogenicity, the fungus was identified as $R$. oryzae. This is the first report of the presence of $R$. oryzae on watermelon in South Korea.

Acknowledgments This work was carried out with the support of the "Cooperative Research Program for Agriculture Science \& Technology Development (Project No. PJ009192)” Rural Development Administration, Korea.

\section{References}

Hall CV (2004) Watermelons as food in the 22 century. In: Nath P, Gaddagimath PB, Dutta OP (eds) Food security and vegetables: a global perspective. Dr. Prem Nath Agricultural Science Foundation, India, pp 135-148

Kwon J-H, Kim J, Lee Y-H, Shim H-S (2010) Soft rot on Cucumis melo var. makuwa caused by Rhizopus oryzae. Mycobiology 38: 336-338

Lunn JA (1977) Rhizopus oryzae. CMI descriptions of pathogenic fungi and bacteria. No. 525. Commonwealth Mycological Institute, Kew

Rimando AM, Perkins-Veazie PM (2005) Determination of citrulline in watermelon rind. J Chromatogr A 1078:196-200 
Roberts P, Kucharck T (2003) Florida plant disease management guide: cucumber. Plant Pathology Department PDMG-V3-38. Florida Cooperative Extension Service, Institute of Food and Agricultural Sciences, University of Florida

Schipper MAA, Stalpers JA (2003) Zygomycetes: the order Mucorales. In: Howard DH (ed) Pathogenic fungi in humans and animals. Marcel Dekker, New York, pp 67-125

Sharma GK, Khan W (1991) Observation on occurrence and identity of powdery mildew of cucurbits in Tamil Nadu. Indian Phytopathol 48: 314-324
Tamura K, Dudley J, Nei M, Kumar S (2007) MEGA4: molecular evolutionary genetics analysis (MEGA) software version 4.0. Mol Biol Evol 24:1596-1599

The Korean Society of Plant Pathology (2009) List of plant diseases in Korea, 5th edn. Korean Society of Plant Pathology, Anyang, 853 pp

White TJ, Bruns T, Lee S, Taylor JW (1990) Amplification and direct sequencing of fungal ribosomal RNA genes for phylogenetics. In: Innis MA, Gelfand DH, Sninsky JJ, White TJ (eds) PCR protocols: a guide to methods and applications. Academic, San Diego, pp 315-322 